\title{
Minimally invasive perventricular device closure of an isolated perimembranous ventricular septal defect with a newly designed delivery system: Preliminary experience
}

Xing Quansheng, MD, ${ }^{\text {a }}$ Pan Silin, MS, ${ }^{a}$ Zhuang Zhongyun, BS, ${ }^{\mathrm{b}}$ Rong Youbao, BS, ${ }^{\mathrm{a}}$ Li Shengde, MS, ${ }^{\mathrm{a}}$ Cao Qian, MS, Duan Shuhua, BS, ${ }^{a}$ Hou Kefeng, BS, ${ }^{a}$ Ji Zhixian, MS, ${ }^{a}$ and Wu Qin, MS ${ }^{\mathrm{a}}$

Objective: We sought to summarize the preliminary clinical experience of minimally invasive transthoracic device closure of perimembranous ventricular septal defects with a new delivery system without cardiopulmonary bypass.

\begin{abstract}
Methods: Twenty-one patients aged 11 months to 12 years (median age, 3.6 years) with isolated perimembranous ventricular septal defects underwent minimally invasive device closure with an inferior sternotomy of 3 to $5 \mathrm{~cm}$ under transesophageal echocardiographic guidance. A single per-right ventricular U-like suture was established, and a new delivery system was introduced, aided by a 16-gauge trocar, including a guidewire, proper sheath, and loading sheath. The proper size of devices was determined by means of transesophageal echocardiographic analysis, and then the device was released under real-time transesophageal echocardiographic monitoring if no significant aortic regurgitation, abnormal atrioventricular valvular motion, or residual interventricular shunt appeared.
\end{abstract}

Results: All of the defects were successfully closed. No residual shunt, noticeable aortic or tricuspid regurgitation, or significant arrhythmias appeared during more than 5 months of follow-up.

Conclusion: Minimally invasive transthoracic device closure of perimembranous ventricular septal defects with a new delivery system without cardiopulmonary bypass is feasible and safe under transesophageal echocardiographic guidance. However, it is necessary to evaluate the intermediate and long-term results.

Earn CME credits at

http://cme.ctsnetjournals.org

Perimembranous ventricular septal defects (PMVSDs) are among the most common congenital cardiac malformations. ${ }^{1,2}$ Closure is routinely performed with cardiac surgical repair aided by cardiopulmonary bypass (CPB), with excellent results. ${ }^{2-4} \mathrm{CPB}$ and sternotomy are important factors that could lead to increased postoperative morbidity, prolonged hospital stay, and possible late neurocognitive impairment. ${ }^{5}$ The longterm effects of CPB remain elusive, and its effects are more pronounced in infants than in patients of older age. ${ }^{6}$

Despite improvements in device closure of PMVSDs, which was introduced in the late $1980 \mathrm{~s},{ }^{7-10}$ transcatheterization intervention for PMVSDs is still associated with long-term morbidity and mortality. In particular, the unascertained potential injury from exposure to $x$-rays is not negligible for children with ventricular septal defects (VSDs).

We describe a new technique to close PMVSDs in which the defects were closed under transesophageal echocardiographic (TEE) guidance without CPB.

From the Pediatric Cardiovascular Centre, ${ }^{\text {a }}$ Qingdao Children's Hospital, Qingdao, China, and Shanghai Co Ltd of Xingzhuangjiyi Alloy Material, ${ }^{\mathrm{b}}$ Shanghai, China. Received for publication Dec 10, 2007; revisions received Feb 24, 2008; accepted for publication May 9, 2008.

Address for reprints: Pan Silin, MS, Pediatric Cardiovascular Center, Qingdao Children's Hospital, Qingdao, Shandong 266011, China (E-mail: silinpan@126.com). J Thorac Cardiovasc Surg 2009;137:556-9

$0022-5223 / \$ 36.00$

Copyright $@ 2009$ by The American Association for Thoracic Surgery doi: $10.1016 /$ j.jtcvs. 2008.05 .073

\section{MATERIALS AND METHODS \\ Patients}

Twenty-one continuous patients with PMVSDs underwent transthoracic minimally invasive device closure without CPB between March and April 2007 aided by a newly designed delivery system. Among these, 13 male children were included (age range, 11 months to 12 years; median age, 3.6 years; weight $15.8 \pm 6.4 \mathrm{~kg}$ ). All of the children tended to be affected by respiratory infection. Systolic murmurs of grade 2 to 3 could be heard in the third intercostal space, with intense pulmonary second heart sounds. As determined with TEE analysis, the dimensions of the PMVSDs were 3 to 12 $\mathrm{mm}$, with enlarged left atria and ventricles. Mild-to-moderate pulmonary hypertension was indicated in 7 patients. The ridges of 2 PMVSDs were adjoined to the aortic valve. X-ray films indicated increased pulmonary blood or prominent congestion, and cardiac profiles extended left inferiorly. Electrocardiograph analysis indicated leftward electrical bore sight in 12 patients.

\section{Devices and Delivery System}

The entire delivery system consists of a trocar, guidewire, dilator and delivery sheath, and a loading sheath (Figure 1) made of polyethylene and acrylonitrile butadiene styrene and disinfected with ethylene oxide. Occluder devices were supplied by Shanghai Co Ltd of Xingzhuangjiyi Alloy Material (no. 20043770007).

\section{Procedure}

The chest was opened through an inferior median sternotomy of 3 to $5 \mathrm{~cm}$ (Figure 2). The pericardium was cradled. A U-like stitch of 4-0 or 5-0 Prolene sutures (Ethicon, Somerville, NJ) was placed on the free wall of the right ventricle. TEE analysis was performed to measure the exact size and location of the PMVSDs. Furthermore, the integrity of the aortic valve was evaluated. A modified short angiocatheter was passed into the right ventricle through the free wall, and then the needle was removed (Figure 3). A 0.035-inch floppy wire was advanced through the angiocatheter and aimed toward the PMVSDs. The PMVSDs were crossed, and the wire was advanced through the defect into the left ventricle. The dilator was removed, and an appropriately sized delivery sheath was advanced over the wire into the left ventricle. The wire and the dilator were removed, 


\section{Abbreviations and Acronyms \\ $\mathrm{CPB}=$ cardiopulmonary bypass \\ PMVSD $=$ perimembranous ventricular septal defect \\ TEE $=$ transesophageal echocardiography \\ TTE $=$ transthoracic echocardiography \\ VSD $=$ ventricular septal defect}

and the sheath was allowed to backbleed to ensure there was no air entrapment (Figure 4). The VSD device was immersed in saline and screwed onto the delivery cable. The device was loaded with the help of a loading sheath. The loading sheath was introduced into the delivery sheath, and the device was advanced to the tip of the sheath. The sheath was gently pulled back until the tip was in the left ventricle, just under the aortic valve. Under echocardiographic guidance, the left disc was deployed; the sheath and the device were pulled back slowly until the left disc approximated the ventricular septum. The device was gently rotated only if the flat part of the disc was not directly under the aortic valve. The waist and the right disc of the occluding device were deployed while maintaining fair traction on the delivery cable. The position of the device was checked, the motion of the aortic valve was evaluated for aortic insufficiency, and the device was released by rotating the delivery cable anticlockwise. The sheath and the delivery cable were pulled out of the right ventricle, and the U-like suture on the right ventricular free wall was tied. TEE was again performed to evaluate tricuspid and aortic regurgitation. The pericardium was partially closed, and a chest tube was placed in the mediastinum. The sternum was closed with special sternal wires. The chest wall was closed in routine fashion. Transthoracic echocardiographic (TTE) analysis was used to evaluate the position of deployed devices, the motion of the aortic and tricuspid valves, and the residual interventricular shunt (Figure 5).

\section{RESULTS}

\section{Intraoperative and Immediate Postoperative Conditions}

The procedure was successful in all patients. There was no incidence of device embolization or heart block. Nineteen cases of isolated PMVSDs were successfully occluded with-

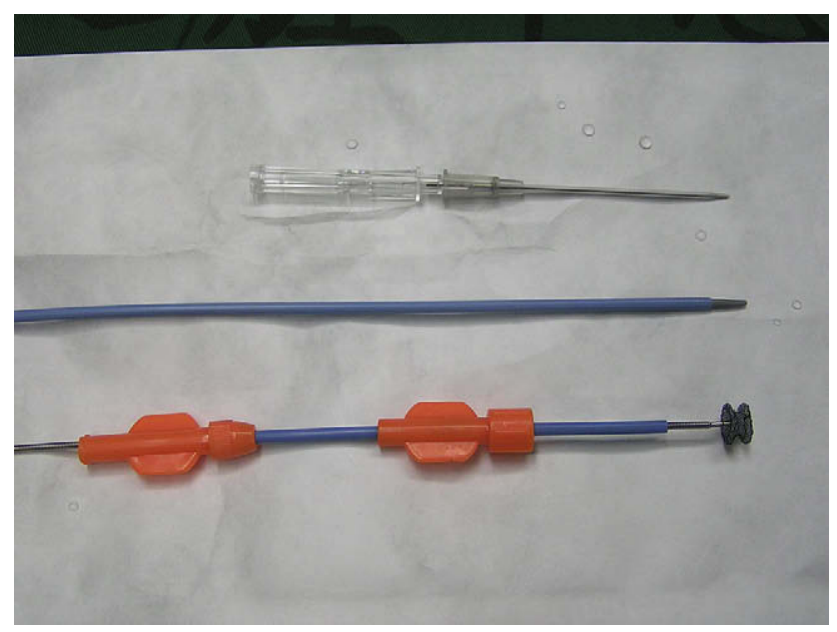

FIGURE 1. Delivery system loading with occluder.

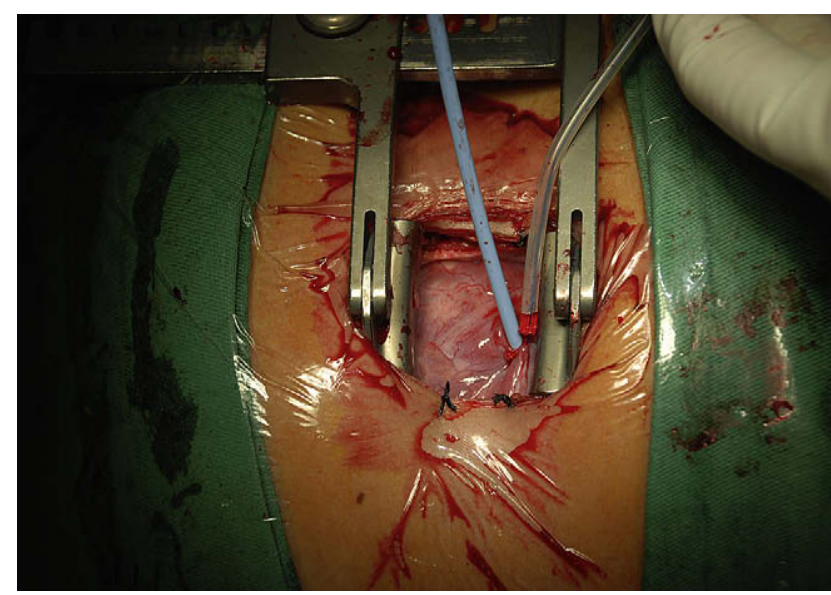

FIGURE 2. Incision.

out transfusion. TEE analysis revealed no residual shunts, abnormal valvular motion, or occluder shift (Figure 5). Symmetric devices were used in 19 cases, and nonsymmetric devices were used in 2 patients whose PMVSD ridges were close to the aortic valve. The diameter of the device waist ranged from 4 to $13 \mathrm{~mm}$. The whole process took less than 60 minutes, and the deployment of the device was finished in less than 30 minutes. The children were extubated in the intensive care unit, except for 3 patients who were extubated on the operating room table no more than 2 hours after the operation. The chest tube was removed 1 to 2 days after the operation. All were extubated and discharged no later than 96 hours. TTE analysis before discharge revealed normal cardiac function and a fixed and proper position of the device without affecting the surrounding tissues.

\section{Follow-up}

Up to now, all patients have undergone more than 5 months of follow-up. Aspirin was administered by mouth at approximately 3 to $5 \mathrm{mg} \cdot \mathrm{kg}^{-1} \cdot \mathrm{d}^{-1}$ during the first 3 months after the operation. Patients were asked to revisit the cardiology unit at least once a month. TTE analysis showed good systolic and diastolic function, proper positioning of the deployed devices, harmonious motion of the aortic and tricuspid valves, and no residual interventricular shunt. There was also no hematuria after the procedure. Normal activities were allowed 2 weeks after discharge.

\section{DISCUSSION}

Thus far, there remain 2 main interventions for PMVSDs: the classical cardiac repair with $\mathrm{CPB}$ and percutaneous transluminal device closure. However, there were noticeable drawbacks for both surgical repair and transcatheterization closure of PMVSDs. When it comes to traditional surgical intervention, great trauma and systemic inflammatory reactions from $\mathrm{CPB}$ are always routine complications. Dangers from 

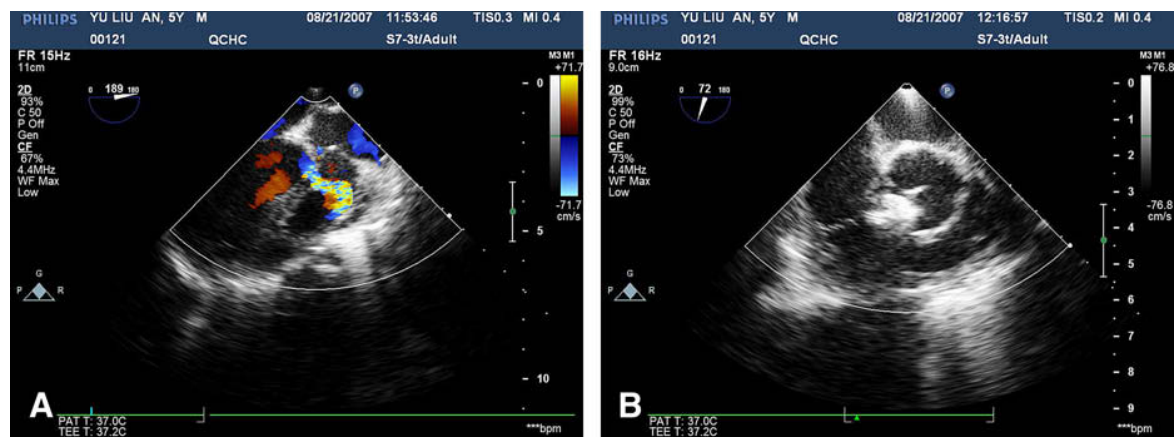

FIGURE 3. U-like right ventricular suture and needle puncture.

intraoperative cardiac arrest are also a great threat. In addition, incision scars not only have an aesthetic effect but also lead to psychologic depression of affected children. Potential negative influences from exposure to $\mathrm{x}$-rays have not been totally avoided for transcatheterization intervention, especially those in who have not conceived, even though protective lead garments have been introduced in these procedures. Simultaneously, limited by thin peripheral veins and the dimension of the device, low-birth-weight young infants are not subjected to this procedure.

Consequently, many have sought to integrate the 2 methods, which is called hybridization, to avoid potential complications from CPB and $\mathrm{x}$-ray exposure. The point is that small inferior sternal and perventricular incisions and TEE monitoring without exposure to $\mathrm{x}$-rays effectively ensure the safe deployment of the device and also greatly decrease morbidity from these traditional procedures. Innovation of the delivery system becomes the core point. In the past 10 years, many physicians in different heart centers, especially those dealing with congenital heart disease, have attempted to design and improve the delivery system. ${ }^{11-14}$

After performing transthoracic minimally invasive device closure of atrial septal defect secundum, ${ }^{15}$ we redesigned the delivery system and succeeded in PMVSD closure. The most prominent character of this new system is its short dimension. It can be held in a single hand so that 1 person can perform the whole procedure. By gently pressing the free wall of the right ventricle, the best point for puncture closest to the PMVSD can be ascertained. It is also possible to adjust the sheath to be parallel to the defect, which decreases the damage to the myocardial and adjacent tissues.

The whole process can be monitored and guided by means of TEE. Once a patient is considered not suitable for such a procedure or the device closure fails, the surgeons can immediately elongate the incision, completely cut open the sternum, and convert to traditional surgical repair without additional incisions or rearranging the operation from the catheterization laboratory to the operating room, which ensures the safety of the procedure. More importantly, such a hybrid intervention is available in almost all types of VSD, including muscular and perimembranous VSDs, even those close to the aortic valve. Intraoperative real-time TEE guidance is another key point. ${ }^{16}$ Almost the total process is dependent on the guidance of clear TEE pictures, and therefore experienced echocardiographers are in great demand. Aided by TEE, dimension of the VSD, adjacent tissue, and valvular structure and motion, especially intraoperative positioning of the delivery system, can be clearly shown.

Therefore performance of transthoracic minimally invasive device closure could be thought of as a great advance for PMVSD closure. Prospectively, with further experience accumulating, more patients with VSDs can benefit from transthoracic minimally invasive device closure.

\section{References}

1. Mitchell SC, Korones SB, Berendes HW. Congenital heart disease I 56,109 births. Circulation. 1971;43:323-32.

2. Kidd L, Driscoll DJ, Gersony WM, Haves CJ, Keane JF, O'Fallon WM, et al. Second natural history study of congenital heart defects: results of treatment of patients with ventricular septal defects. Circulation. 1993;87(suppl I):138-51.

3. Rudolph AM. Ventricular septal defect. In: Rudolph AM, ed. Congenital diseases of the heart: clinical-physiological considerations. 2nd ed. Armonk (NY): Futura; 2000. p. 197-244.

4. Backers CL, Winters RC, Zales VR, Takami H, Muster AJ, Benson DW Jr, et al. The restrictive ventricular septal defect: how small is too small to close? Ann Thorac Surg. 1993;56:10-4.

5. Rose EA. Off-pump coronary artery bypass surgery. $N$ Engl J Med. 2003;348: 379-80.

6. Kern FH, Hickey PR. The effects of cardiopulmonary bypass on the brain. In: Jonas RA, ed. Cardiopulmonary bypass in neonates, infants and young children. 1st ed. Boston: Blackwell Science; 1994. p. 263-78.

7. Lock JE, Block PC, McKay RG, Baim DS, Keane JF. Transcatheter closure of ventricular septal defects. Circulation. 1988;78:361-8.

8. Janorkar S, Goh T, Wilkinson J. Transcatheter closure of ventricular septal defects using the Rashkind device: initial experience. Catheter Cardiovasc Interv. 1999;46: 43-8.

9. Kalra GS, Verma PK, Dhall A, Singh S, Arora R. Transcatheter device closure of ventricular septal defects: immediate results and intermediate-term follow-up. Am Heart J. 1999;138:339-44.

10. Sideris EB, Walsh KP, Haddad JL, Chen CR, Ren SG, Kulkarni H. Occlusion of congenital ventricular septal defects by the buttoned device. "Buttoned Device", Clinical Trials International Register. Heart. 1997;77:276-9.

11. Amin Z, Gu X, Berry JM, Titus JL, Gidding SS, Rocchini AP. Perventricular closure of ventricular septal defects without cardiopulmonary bypass. Ann Thorac Surg. 1999;68:149-53.

12. Amin Z, Danford DA, Lof J, Duncan KF, Froemming S. Intraoperative device closure of perimembranous ventricular septal defects without cardiopulmonary bypass: preliminary results with the perventricular technique. $J$ Thorac Cardiovasc Surg. 2004;127:234-41. 
13. Amin Z, Woo R, Danford DA, Froemming SE, Reddy VM, Lof J, et al. Robotically assisted perventricular closure of perimembranous ventricular septal defects: preliminary results in Yucatan pigs. J Thorac Cardiovasc Surg. 2006;131:427-32.

14. Bacha EA, Cao QL, Starr JP, Waight D, Ebeid MR, Hijazi ZM. Perventricular device closure of muscular ventricular septal defects on the beating heart: technique and results. J Thorac Cardiovasc Surg. 2003;126:1718-23.
15. Duan SH, Xing QS, Rong YB, Cao Q, Hou KF. Application of transthoracic minimally invasive techniques in device closure of atrial septal defect without cardiopulmonary bypass. Int J Cardiovasc Dis. 2005;32:305-6.

16. Pan SL, Xing QS, Rong YB, Cao Q, Wang KL, Liu XQ. Application of real-time three-dimensional echocardiography in hybrid treatment of atrial septal defect. Chin J Ultrasound. 2007;23:543-5. 